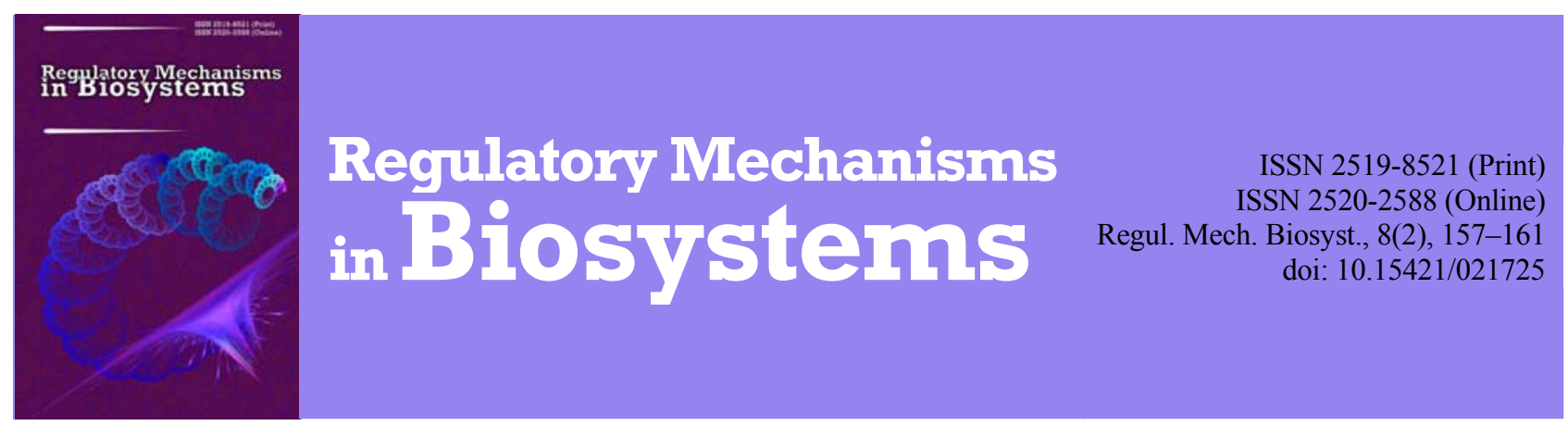

\title{
Glutathione content in sperm cells of infertile men
}

\author{
R. V. Fafula, O. K. Onufrovych, U. P. Iefremova, O. V. Melnyk, I. A. Nakonechnyi, D. Z. Vorobets, Z. D. Vorobets \\ Danylo Halytsky Lviv National Medical University, Lviv, Ukraine
}

Article info

Received 27.03.2017

Received in revised form 19.04.2017

Accepted 22.04.2017

Danylo Halytsky Lviv

National Medical University,

Pekarska Str., 69

Lviv, 79010, Ukraine.

Tel.: +38-097-29-680-69.

E-mail:roman_fafula@ukr.net

\begin{abstract}
Fafula, R. V., Onufrovych, O. K., Iefremova, U. P., Melnyk, O. V., Nakonechnyi, I. A., Vorobets, D. Z., \& Vorobets, Z. D. (2017). Glutathione content in sperm cells of infertile men. Regulatory Mechanisms in Biosystems, 8(2), 157161. doi:10.15421/021725
\end{abstract}

Hyperproduction of reactive oxygen species can damage sperm cells and is considered to be one of the mechanisms of male infertility. Cell protection from the damaging effects of free radicals and lipid peroxidation products is generally determined by the degree of antioxidant protection. Glutathione is non-enzymatic antioxidant which plays an important protective role against oxidative damages and lipid peroxidation. The aim of the present work is to determine the content of reduced and oxidized glutathione in sperm cells of infertile men. Semen samples from 20 fertile men (normozoospermics) and 72 infertile patients (12 oligozoospermics, 17 asthenozoospermics, 10 oligoasthenozoospermics and 33 leucocytospermic) were used. The total, oxidized (GSSG) and reduced (GSH) glutathione levels were measured spectrophotometrically. The levels of total glutathione were significantly lower in the spermatozoa of patients with oligozoo-, asthenozoo- and oligoasthenozoospermia than in the control. Infertile groups showed significantly decreased values of reduced glutathione in sperm cells vs. fertile men, indicating an alteration of oxidative status. The oxidized glutathione levels in sperm cells of infertile men did not differ from those of normozoospermic men with proven fertility. The GSH/GSSG ratio was significantly decreased in the oligo-, astheno- and oligoasthenozoospermic groups compared to the normozoospermic group. In patients with leucocytospermia the GSH/GSSG ratio was lowered, but these changes were not significant. In addition, the glutathione peroxidase activity in sperm cells was decreased in patients with oligozoo-, astenozoo-, oligoastenozoospermia and with leucocytospermia. The most significant changes in glutathione peroxidase activity were observed in infertile men with leucocytospermia. Decreased GSH/GSSG ratio indicates a decline in redox-potential of the glutathione system in sperm cells of men with decreased fertilizing potential. Redistribution between oxidized and reduced forms of glutathione can be caused by depletion of intracellular stores of glutathione and intensification of lipid peroxidation processes. This leads to increased production of reactive oxygen species, further depletion of antioxidant pools and disturbances of structure and function of spermatozoa. Our results indicate that the evaluation of reduced glutathione level and GSH/GSSG ratio in sperm cells of infertile men can be helpful in fertility assessment.

Keywords: glutathione; glutathione peroxidase; spermatozoa; pathospermia; male infertility

\section{Introduction}

It is well known that the processes of lipid peroxidation are universal mechanisms of cell damage. However, the physiological levels of lipid peroxidation are necessary for normal functioning of almost all cells. Cell protection from the damaging effects of free radicals and lipid peroxidation products is generally determined by the degree of antioxidant protection. Under physiological norm a balance between the rate (intensity) of free radical processes and the activity of antioxidant systems is maintained.

Reduced glutathione (GSH) and associated enzymes that form the glutathione antioxidant system are of particular importance in maintaining cell viability in antiradical and antiperoxide protection. The glutathione antioxidant system plays a leading role in antioxidant protection under pathological processes. Depletion of the glutathione system leads to cytotoxic and destructive lesions (Kalinina et al., 2014). Reduced glutathione exists in cells in equilibrium with oxidized glutathione (GSSH) and the GSH/GSSH ratio characterizes the redox state of the system in different physiological states (Kurilova et al., 2008). GSH is present in the cell at high concentrations and is a major low molecular weight thiol under physiological conditions. It is known that GSH is the main component that quickly mobilizes at higher peroxide concentrations and restores them in the reaction leading to the formation of cytotoxic GSSG (Koval et al., 2008). The GSH content in cell depends on the balance of opposing processes such as de novo synthesis by gamma-glutamylcysteine synthetase, regeneration of GSSG by glutathionreductase and usage in neutralizing of $\mathrm{H}_{2} \mathrm{O}_{2}$ and secondary lipid peroxidation products (Iskra, 2011).

Determination of the glutathione level in sperm cells of infertile men and its relation to changes in the spermatogram index have been carried out in several studies published before. However, the in vast majority of studies the glutathione level was determined in seminal plasma, but not in spermatozoa, and the results of these studies were controversial (Lewis et al., 1997; Ochsendorf et al., 1998; Garrido et al., 2004; Ebisch et al., 2006; Aydemir et al., 2007).

The aim of present work is to determine the content of reduced and oxidized glutathione in sperm cells of infertile men with different forms of pathospermia.

\section{Materials and methods}

Patients. This study involved 72 infertile men with different forms of pathospermia. They were recruited between 2014 and 2016. 
A detailed medical history was performed for all studied cases. Exclusion criteria: subjects currently on any medication or antioxidant supplementation were not included. In addition, subjects with infertility lasting over 10 years, azoospermia, testicular varicocele, genital infection, chronic illness and serious systemic diseases, smokers and alcoholic men were excluded from the study because of their well-known high seminal reactive oxygen species (ROS) levels and decreased antioxidant activity (Atig et al., 2012).

Ejaculates from a total of 72 infertile and 20 fertile healthy individuals were obtained. The control group consisted of 20 healthy men with somatic fertility, normozoospermia and confirmed parenthood (married for 3-10 years and had healthy 1-3 children). Semen samples were obtained by masturbation and collected into sterile containers, following 3-5 days' abstinence from sexual activity. After liquefaction at $37{ }^{\circ} \mathrm{C}$ with $5 \% \mathrm{CO}_{2}$ in air, semen samples were examined for volume, sperm concentration, $\mathrm{pH}$, morphology and motility according to the World Health Organization guidelines. Before becoming involved in the study, all the men were familiarized with patient information leaflets and gave informed consent to participate in research. Terms of sample selection meet the requirements of the principles of the Helsinki Declaration on Protection of Human Rights, Convention of Europe Council on human rights and biomedicine and the provisions of laws of Ukraine. Approval for the study was taken from the ethics committe of Danylo Halytsky Lviv National Medical University.

According to semen analysis, oligozoospermia was found in 12 patients $(16.7 \%)$, asthenozoospermia was detected in 17 patients (23.6\%), oligoasthenozoospermia was observed in 10 patients (13.9\%). Thirty-nine (54.2\%) infertile men had leukocytes content in the semen lower than $1.0 \cdot 10^{6} \mathrm{ml}^{-1}$, only in 33 patients $(45.8 \%)$ was leukocytospermia noted (the leukocytes content ranged from $1.0 \cdot 10^{6} \mathrm{ml}^{-1}$ to $3.0 \cdot 10^{6} \mathrm{ml}^{-1}$ ) which indicates inflammation in this group of men.

Cell preparation. Sperm cells were washed from semen plasma by 3 times centrifugation at $3,000 \mathrm{~g}$ for $10 \mathrm{~min}$ in media which contained (mM): $120 \mathrm{NaCl}, 30 \mathrm{KCl}, 30$ Hepes (pH 7.4). The content of total protein in the samples was determined by Lowry method using a kit to determine its concentration ("Simko Ltd"). The detergent saponin in a final concentration of $0.5 \%$ was added to sperm suspension for permeabilization of sperm membranes.

Assay of glutathione content and glutathione peroxidase activity. The content of total glutathione was determined in saponinpermiabilized spermatozoa after complete reduction of glutathione through the use of glutathione reductase by means of Ellman's reagent (Anderson, 1985). The level of 5-trinitrobenzoic acid was monitored with a spectrophotometer at $412 \mathrm{~nm}$. To determine the content of oxidized glutathione (GSSG), 2-vinylpyridine was added to the incubation mixture to a final concentration of $2 \% 60 \mathrm{~min}$ before the determination (Griffith, 1980). The content of reduced glutathione (GSH) was calculated as the difference of contents between total glutathione and its oxidized form. Glutathione peroxidase activity was determined by the oxidation of glutathione.

Statistical analysis. Experimental data were processed by methods of variation statistics using software MS Office. The results are presented as the mean \pm standard deviation of the mean. Analysis of variance (ANOVA) was used to compare the difference in the means between infertile and healthy men. Differences were considered statistically significant at $\mathrm{P}<0.05$ for all analyses.

\section{Results}

We found that in patients with normozoospermia the GSHt content in sperm cells was $36.5 \pm 4.1$ pmol of $\mathrm{GSH} / 106$ cells (Fig. 1). Patients with oligozoospermia showed 1.9-fold lower GSHt content $\left(19.2 \pm 2.1 \mathrm{pmol}\right.$ of $\mathrm{GSH} / 10^{6}$ cells $)$ than did control subjects, whereas patients with asthenozoospermia showed 1.8-fold lower GSHt content $\left(20.8 \pm 1.9 \mathrm{pmol}\right.$ of $\mathrm{GSH} / 10^{6}$ cells $)$ than control subjects. In patients with oligoasthenozoospermia GSHt content was $21.7 \pm 2.7 \mathrm{pmol}$ of $\mathrm{GSH} / 10^{6}$ cells which was 1.7 -fold lower than in normozoospermic men with proven fertility. The GSHt content was 1.2 -fold lower $\left(29.8 \pm 2.3\right.$ pmol GSH/10 $0^{6}$ cells $)$ in leucocytospermic patients vs men with normozoospermia, but these changes were not significant.

The content of GSH in sperm cells of fertile men was $34.0 \pm$ $4.0 \mathrm{pmol} / 10^{6}$ cells (Fig. 2). We found the decreased GSH level in sperm cells of infertile men with different forms of pathospermia. However, the most expressed changes in the GSH content were observed in patients with oligozoospermia.

The GSH content decreased to $16.8 \pm 1.9 \mathrm{pmol}$ of GSH/10 cells, which was twice lower than in normozoospermic men with proven fertility. In patients with asthenozoospermia and oligoasthenozoospermia the GSH level was $17.5 \pm 1.8$ and $18.3 \pm$ $2.6 \mathrm{pmol}$ of $\mathrm{GSH} / 10^{6}$ cells that was 1.9 -fold lower than control group. In leucocytospermic patients the GSH level was $27.1 \pm 2.2$ pmol of $\mathrm{GSH} / 10^{6}$ cells which was 1.3 -fold lower than in patients with normozoospermia, but these changes were not significant.

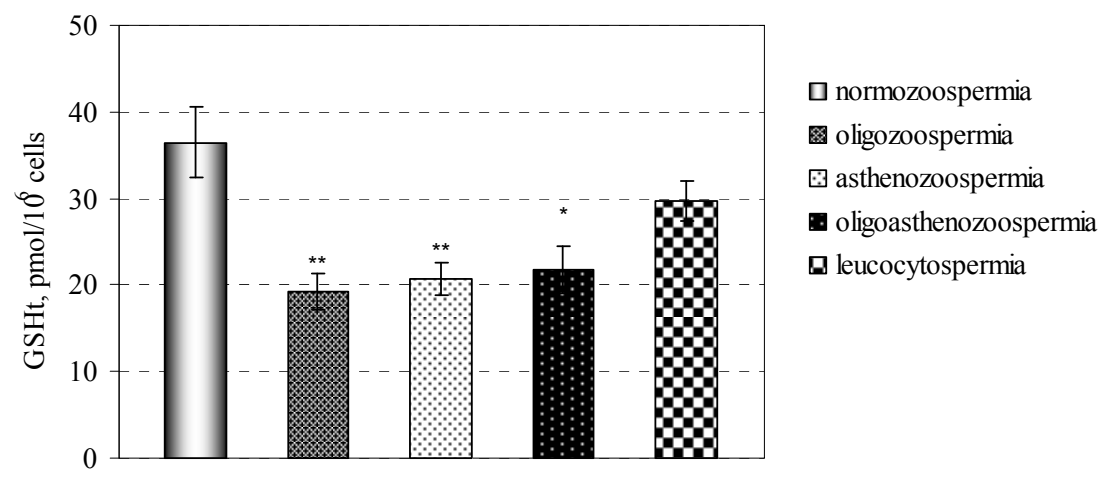

Fig. 1. The content of total glutathione in the sperm cells of infertile men with different forms of pathospermia:

the results are presented as the mean \pm standard deviation of the mean, $\mathrm{n}=10-33$; ANOVA was used; asterisks indicate the values that are significantly different from control group (normozoospermia); ${ }^{*}-\mathrm{P}<0.05,{ }^{* *}-\mathrm{P}<0.01,{ }^{* * *}-\mathrm{P}<0.001$ relative to the control group

The GSSG content in sperm cells of normozoospermic and oligozoospermic men was $2.5 \pm 0.3$ pmol GSSG/10 6 cells (Fig. 3). The content of oxidized forms of glutathione in spermatozoa in infertile men of other studied groups was increased, but these changes were not statistically significant. Patients with astheno-, oligoasthenozoospermia and leucocytospermia showed 1.3-, 1.4- and 1.1-fold higher GSSH content $(3.3 \pm 0.4,3.4 \pm 0.5$ and $2.7 \pm 0.3$ pmol of GSSG $/ 10^{6}$ cells correspondingly) than did control subjects.
In addition to determination of GSHt, GSH and GSSG, the ratio of reduced to oxidized glutathione (GSH/GSSG ratio) was calculated from these measurements (Fig. 4). It is a more sensitive indicator of pro- and antioxidant status. The GSH/GSSG ratio in patients with normozoopermia was $15.2 \pm 1.9$. The ratio of the reduced to oxidized form of glutathione in the spermatozoa of men with oligo-, astheno- and oligoasthenozoospermia was much lower than in men with normozoospermia $(7.2 \pm 0.9,6.1 \pm 0.9$ and $6.4 \pm$ 
1.2 respectively). The GSH/GSSG ratio is somewhat lower in patients with leukocytospermia $(12.1 \pm 0.9)$. The ratio of the reduced to oxidized form of glutathione indicates a decrease in total capacity of the glutathione system in sperm cells of men with decreased fertilizing potential. The glutathione peroxidase activity was significantly decreased in patients with all forms of patho- spermia compared with healthy men with proven fertility (Fig. 5). The enzyme activity in patients with oligozoospermia was $44 \%$ and in patients with astenozoo- and oligoastenozoospermia $35 \%$ of that in normozoospermic men. The most significant changes in glutathione peroxidase activity were observed in infertile men with leucocytospermia ( $26 \%$ of activity in normozoospermic men).

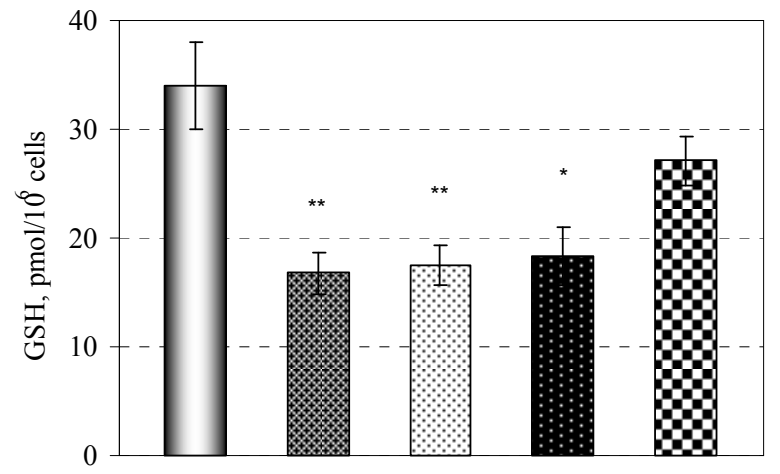

$\square$ normozoospermia

图 oligozoospermia

[. asthenozoospermia

oligoasthenozoospermia

由 leucocytospermia

Fig. 2. The content of reduced glutathione in sperm cells of infertile men with different forms of pathospermia: see Fig. 1 description

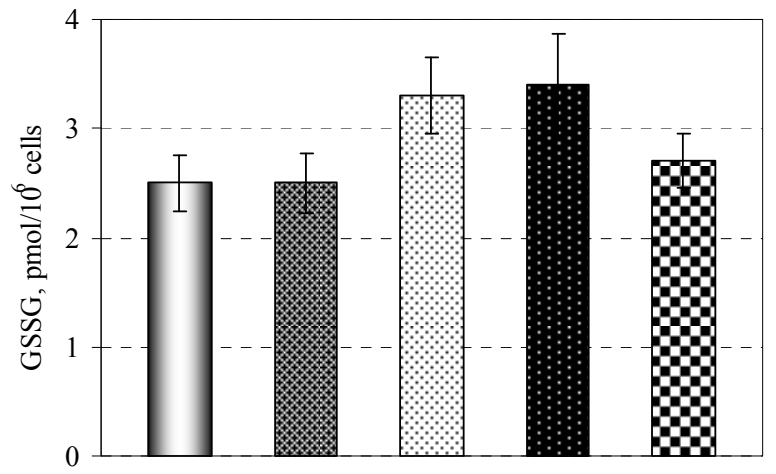

$\square$ normozoospermia

oligozoospermia

웡 asthenozoospermia

a oligoasthenozoospermia

Q leucocytospermia

Fig. 3. The content of oxidized glutathione in sperm cells of infertile men with different forms of pathospermia: see Fig. 1 description

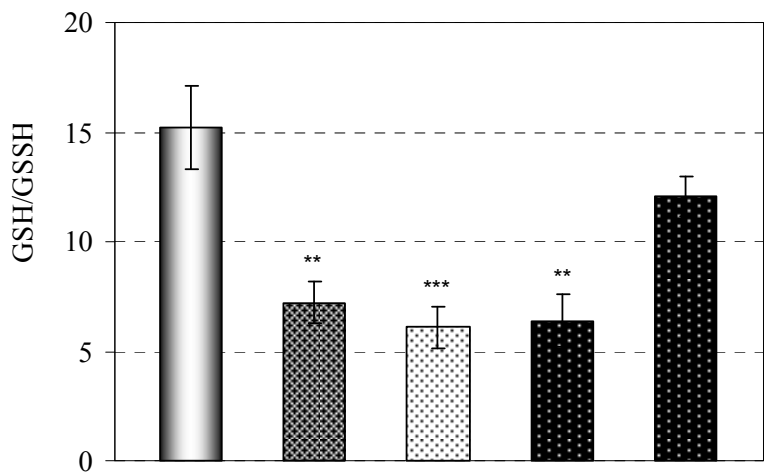

\section{$\square$ normozoospermia}

图 oligozoospermia

asthenozoospermia

D oligoasthenozoospermia

a leucocytospermia

Fig. 4. The GSH/GSSG ratio in sperm cells of infertile men with different forms of pathospermia: see Fig. 1 description

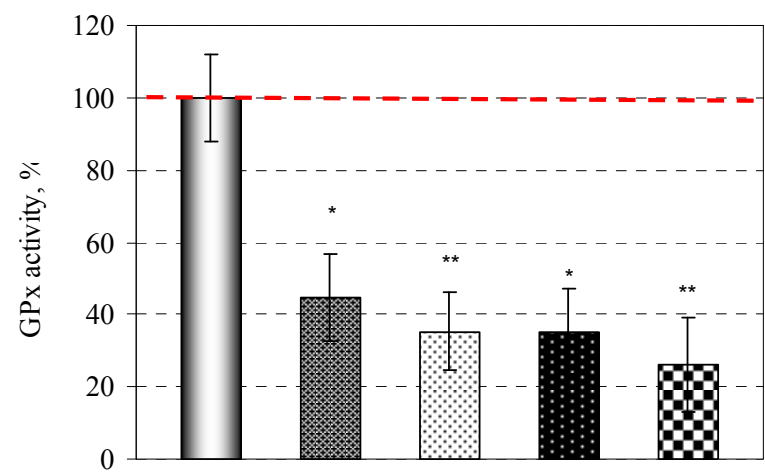

$\square$ normozoospermia

圈 oligozoospermia

[7 asthenozoospermia

B oligoasthenozoospermia

ⓛeucocytospermia

Fig. 5. Glutathione peroxidase activity in sperm cells of infertile men with different forms of pathospermia: see Fig. 1 description

\section{Discussion}

Other findings about GSH level in sperm cells are controversial. Overall, our results are consistent with several other studies. In particular, it was shown that GSH content in sperm cells of patients with oligozoospermia was significantly lower than in control group (Ochsendorf et al., 1998). Reduced intracellular GSH was observed in sperm of infertile men, but these differences were not statistically 
significant (Garrido et al., 2004). However, the same study found the presence of a moderate direct correlation between the GSH content and disturbance of sperm morphology. In addition, it was shown that intracellular GSH content in sperm cells of in smokers was lower compared with nonsmokers (Viloria et al., 2010).

However, conflicting data have been obtained in other studies. Ebisch et al. (2007) revealed high GSH content in spermatozoa of subfertile men compared to fertile men. Lewis et al. (1997) showed that the content of sulfhydryl compounds was significantly higher in spermatozoa from men with asthenozoospermia than in men with normozoospermia. According to the researchers the increased synthesis of thiol compounds is a compensatory mechanism to protect cell from oxidative damage. Aydemir et al. (2007) found no statistically significant differences in the values of intracellular GSH between patients with idiopathic infertility and healthy men.

Conflicting data have also been obtained about GSH content in seminal plasma of men with infertility. A large number of studies have found no statistically significant differences between GSH content in seminal plasma of fertile and infertile men (Aydemir et al., 2007; Wong et al., 2001; Ebisch et al., 2006). Hesham et al. (2008) established a significant reduction of GSH in seminal plasma of men with azoospermia and oligozoospermia. A decrease in GSHt and GSH content was found in seminal plasma of men with asthenozoospermia. However, the same study showed a slight increase in GSH level in patients with combined form of pathospermia (oligoasthenozoospermia) with simultaneous decrease of oxidized form (GSSG) (Atig et al., 2012). In men with violations of spermatogenesis by oligozoospermia, the GSH content was decreased, but these differences were not statistically significant (Atig et al., 2012). A reduction of GSH was found in seminal plasma in men with azoospermia and oligozoospermia (Bhardwaj et al., 2000). The GSH/GSSG ratio was lower in seminal plasma of men with idiopathic infertility and varicocele than in healthy men (Micheli et al., 2016). On the contrary, other studies found an increase in GSH content in seminal plasma of men with azoospermia (Ochsendorf et al., 1998). Also, Raijmakers et al. (2003) showed that GSH content was higher in seminal plasma of fertile than in subfertile men.

These differences can be explained by the controversial inclusion and exclusion criteria for patients in the studied groups, different analytical approaches (techniques), patients' lifestyle, their habitats, health, diet, origin etc.

Taking into account that GSH not only protects cells from toxic free radicals, but in general determines oxidation-reduction characteristics of intracellular environment, reduction in GSH content indicates a decrease in antioxidant capacity. This leads to increased ROS production, further depletion of the pool of bioantioxidants and increased lipid peroxidation, which causes violations of the structure and functions of spermatozoa.

Reduced glutathione plays a leading role in the antioxidant defense (Korzhov and Zhadan, 2007). Its antioxidative properties are due to a direct interaction with ROS and functioning of glutathione-dependent enzymes such as glutathione peroxidase and glutathione transferase. Glutathione peroxidase catalyzes the reduction of $\mathrm{H}_{2} \mathrm{O}_{2}$ or organic hydroperoxide, using reduced glutathione. As it is well known, glutathione peroxidase is a key antioxidant enzyme which regulates ROS levels and protects sperm cells from lipid peroxidation and oxidative stress. In fact, we showed that glutathione peroxidase activity was significantly decreased in patients with all forms of pathospermia compared with healthy men with normozoospermia.

The intensity of free radical reactions and processes depends on the concentration of oxygen and the functioning of the enzymatic and nonenzymatic antioxidant systems. In our previous studies (Onufrovych et al., 2016; Fafula et al., 2017) we found depletion of antioxidant systems in particular inhibition of glutathione peroxidase, glutathione reductase and glutathione transferase in spermatozoa of infertile men. Despite the fact that the enzymatic component of the antioxidant protection system is more sensitive to changes in prooxidant-antioxidant balance than nonenzymatic, both systems are closely related. On the one hand, nonenzymatic antioxidants are substrates of reactions catalyzed by antioxidant enzymes. On the other hand, as a result of enzymes work the number nonenzymatic factors constantly increases and their level depends on physiological needs of the cell. Therefore, it the dynamic balance between content of nonenzyme components and activity enzymatic systems is essential.

In addition, the reduction of GSH in sperm cells of infertile men may be due to low activity of glutathione reductase, which indicates the inactivation of GSH regeneration. It is well known that glutathione reductase uses NADPH as a restored equivalent, the content of which is reduced under conditions of oxidative stress (De Minicis and Brenner, 2008). It is also known that GSH/GSSG ratio decreases rapidly under oxidative stress, leading to structural defects and functional changes unless NADPH-dependent of GSH regeneration occurs (Mendez et al., 2016).

It should be noted that GSH/GSSG ratio is significantly higher in leucocytospermic patients than in other pathologies. According to other researchers (Micheli et al., 2016) who found similar results in infertile men with infectious factor, a slight decrease in GSH level and maintaining GSH/GSSG balance is "sparing effect" caused by another nonenzymatic antioxidant - ascorbic acid (vitamin C). However, this effect is not a sufficiently powerful mechanism to neutralize ROS hyperproduction and development of oxidative stress which is evidenced by extremely high content of thiobarbituric acid reactive substances in sperm cells of patients with leucocytospermia (Fafula et al., 2017). The consequence of reduction of GSH can be $\mathrm{H}_{2} \mathrm{O}_{2}$ accumulation enhanced with subsequent production of hydroxile radical and damage of macromolecular structures. In particular, it was shown that prolonged intensification of lipid peroxidation is accompanied by the accumulation of malondialdehyde and 4-hydroxynonenal that can bind to DNA and proteins, modifying their structure and disrupting the function (Hubskyi, 2015; Spickett, 2013). GSSH reacts with thiol groups of proteins with production of mixed disulfides that can alter the catalytic properties of enzymes which is manifested by their ability to maintain adaptive response to stress (Smirnov and Suhovskaya, 2014).

Thus, the changes in GSH content and activities of enzymes of its metabolism found in sperm cells (Onufrovych et al., 2016; Fafula et al., 2017) in patients with pathospermia may be interpreted as a response to development of oxidative stress. Decrease in intracellular GSH level and inhibition of glutathione peroxidase leads to overproduction of ROS which results in oxidative stress and injury in sperm cells.

Inhibition of antioxidant enzymes activities, a decrease in GSH and enhanced lipid peroxidation indicate an irreversible destructive changes (Mishchuk and Stolyar, 2008). Thus, the destabilization of the glutathione system promotes even greater intensification of lipid peroxidation processes and destruction of spermatozoa. Sperm motility is associated with excessive oxidation of sulfhydryl groups that are part of GSH (Atig et al., 2012). GSH is localized mainly in the middle part and tail of spermatozoon, which ensure its mobility (Eskiocak et al., 2005).

Determination of GSH and the GSH/GSSG ratio can be used as an additional biochemical indicator for the assessment of men's potential to father children. Disturbance in the glutathione system in spermatozoa is a one of the pathogenetic mechanisms leading to infertlity that must be considered when using antioxidants in the treatment of male infertility.

\section{Conclusions}

Under conditions of pathospermia the reduced glutathione content in spermatozoa decreased, which led to depletion of reduction potential of the glutathione antioxidant system. Redistribution between oxidized and reduced forms of glutathione can be caused by depletion of intracellular GSH stores and intensification of lipid peroxidation processes. 


\section{Support and acknowledgements}

The publication contains the results of studies conducted under the President's of Ukraine grant for competitive projects (project No $\Phi 63 / 97-2016$ from 10.08.2016 "Molecular biological regulatory mechanisms of disturbance of fertilizing ability spermatozoa and the development of new immuno-biochemical diagnostic methods of fertility in men" (scientific supervisor - Doc. Sci. D. Vorobets) of the State Fund for Fundamental Research (The President's Order No 97/2016-рп dated: April 13, 2016).

\section{References}

Anderson, M. E. (1985). Determination of glutathione and glutathione disulfide in biological samples. Methods in Enzymology, 113, 548-555.

Atig, F., Raffa, M., Habib, B.-A., Kerkeni, A., Saad, A., \& Ajina, M. (2012). Altered antioxidant status and increased lipid perxidation in seminal plasma of Tunisian infertile men. International Journal of Biological Sciences, 8(1), 139-149.

Atig, F., Raffa, M., Habib, B.-A., Kerkeni, A., Saad, A., \& Ajina, M. (2012). Impact of seminal trace element and glutathione levels on semen quality of Tunisian infertile men. BMC Urology, 12, 6.

Aydemir, B., Onaran, I., Kiziler, A. R., Alici, B., \& Akyolcu, M. C. (2007). Increased oxidative damage of sperm and seminal plasma in men with idiopathic infertility is higher in patients with glutathione S-transferase Mu-1 null genotype. Asian Journal of Andrology, 9(1), 108-115.

Bhardwaj, A., Verma, A., Majumdar, S., \& Khanduja, K. L. (2000). Status of vitamin $\mathrm{E}$ and reduced glutathione in semen of oligozoospermic and azoospermic patients. Asian Journal of Andrology, 2(3), 225-228.

De Minicis, S., \& Brenner, D. A. (2008). Oxidative stress in alcoholic liver disease: Role of NADPH oxidase complex. Journal of Gastroenterology and Hepatology, 1, 98-103.

Ebisch, I. M. W., Peters, W. H. M., Thomas, C. M. G., Wetzels, A. M., Peer, P. G., \& Steegers-Theunissen, R. P. (2006). Homocysteine, glutathione and related thiols affect fertility parameters in the subfertile couple. Human Reproduction, 21, 1725-1733.

Eskiocak, S., Gozen, A. S., Yapar, S. B., Tavas, F., Kilic, A. S., \& Eskiocak, M. (2005). Glutathione and free sulphydryl content of seminal plasma in healthy medical students during and after exam stress. Human Reproduction, 9, 2595-6000.

Fafula, R. V., Onufrovych, O. K., Vorobets, D. Z., Iefremova, U. P., \& Vorobets, Z. D. (2017). Glutathione antioxidant protection system in ejaculated spermatozoa of infertile men with different forms of pathospermia. Studia Biologica, 11(1), 17-24.

Garrido, N., Meseguer, M., Alvarez, J., Simón, C., Pellicer, A., \& Remohí, J. (2004). Relationship among standard semen parameters, glutathione peroxidase / glutathione reductase activity, and mRNA expression and reduced glutathione content in ejaculated spermatozoa from fertile and infertile men. Fertility and Sterility, 82(3), 1059-1066.

Griffith, O. W. (1980). Determination of glutathione and glutathione disulfide using glutathione reductase and 2-vinylpyridine. Analytical Biochemistry, 106, 207-212.

Hesham, N., Moemen, L. A., \& Abu Elela, M. H. (2008). Studing the levels of malondialdehyde and antioxidant parameters in normal and abnormal human seminal plasma. Australian Journal of Basic and Applied Sciences, 2(3), 773-778.

Hubskyi, Y. I. (2015). Smert kletki: Svobodnie radically, necros, apoptos [Cell death: Free radicals, necrosis, apoptosis]. Nova Knyga, Vynnyca (in Russian).

Iskra, R. J. (2011). Stan glutationovoi lanky antioxidantnoi systemy v riznyh organah i tkanynah szuriv za dii nanoacqucytratu chromu [State of glutathione component of the antioxidant system in different organs and tissues of rats under the influence of chromium nanoaquarcitate]. Experimental and Clinical Physiology and Biochemistry, 3, 28-33 (in Ukrainian).

Iskra, R. J. (2011). State of glutathione component of the antioxidant system in different organs and tissues of rats under the influence of chromium nanoaquarcitate. Experimental and Clinical Physiology and Biochemistry, 3, 28-33.

Kalinina, E. V., Chernov, N. N., \& Novichkova, M. D. (2014). Role of glutathione, glutathione transferase and glutaredoxin in regulation of redox-dependent processes. Biochemistry, 79(13), 1562-1583.

Korzhov, V. I., \& Zhadan, V. N. (2007). Rol systemy glutationa v processah detoxikacii i antioxidantnoi zaszyty [Role of the glutathione system in the processes of detoxification and antioxidant protection]. Journal of Academy of Medical Sciences of Ukraine, 13, 3-19 (in Russian).

Koval, T. V., Nazarova, O. O., \& Matyshevska, O. P. (2008). Zmina vmistu glutationu v timocytah szuriv za indukcii apoptosu pid vplyvom $\mathrm{H}_{2} \mathrm{O}_{2}$ abo radiacii [Change in glutathione content in rat thymocytes under apoptosis induced by $\mathrm{H}_{2} \mathrm{O}_{2}$ or $\mathrm{X}$ irradiation]. Ukrainian Biochemical Journal, 80(2), 114-119 (in Ukrainian).

Kurilova, L. C., Krutetskaya, Z. I., Lebedev, O. E., \& Antonov, V. H. (2008). Vliyanie okislennogo glutationa i ego farmokologicheskogo analoga preparata glutoksim na vnitrikletochnuyu koncentraciu $\mathrm{Ca}^{2+} \mathrm{v}$ macrofagah [The effect of oxidized glutathione and its pharmacological analogue, glutoxim, on intracellular $\mathrm{Ca}^{2+}$ concentration in macrophages]. Cytology, 50(5), 452-461 (in Russian).

Lewis, S. E., Sterling, E. S., Young, I. S., \& Thompson, W. (1997). Comparison of individual antioxidants of sperm and seminal plasma in fertile and infertile men. Fertility and Sterility, 67(1), 142-147.

Lowry, O. H., Rosebrough, N. J., Farr, A. L., \& Randall, R. J. (1951). Protein measurement with the Folin phenolreagent. Journal of Biological Chemistry, 193, 265-275.

Mendez, I., Vázquez-Martínez, O., Hernández-Muñoz, R., Valente-Godínez, H., \& Díaz-Muñoz, M. (2016). Redox regulation and pro-oxidant reactions in the physiology of circadian systems. Biochemie, 124, 178-186.

Micheli, L., Cerretani, D., Collodel, G., Menchiari, A., Moltoni, L., Fiaschi, A. I., \& Moretti, E. (2016). Evaluation of enzymatic and non-enzymatic antioxidants in seminal plasma of men with genitourinary infections, varicocele and idiopathic infertility. Andrology, 4(3), 456-464.

Mishchuk, O. V., \& Stolyar, O. B. (2008). Vpliv pesticidu acetamipridu na biochimichni pokaznyky u tkanynah prisnovodnogo dvostulkovogo moluska Anodonta cygnea L. (Unionidae) [The effect of the pesticide acetamiprid on the status of biochemical markers in tissues of freshwater bivalve mussels Anodonta cygnea L. (Unionidae)]. Ukrainian Biochemical Journal, 80(5), 117-124 (in Ukrainian).

Ochsendorf, F. R., Buhl, R., Bästlein, A., \& Beschmann, H. (1998). Glutathione in spermatozoa and seminal plasma of infertile men. Human Reproduction, 13(2), 353-359.

Onufrovych, O. K., Fafula, R. V., Nakonechnyi, I. A., Vorobets, D. Z., Iefremova, U. P., \& Vorobets, Z. D. (2016). Activnist glutation-zalezhyh enzymiv spermatozoidiv za umov patospermii [Activity of glutathione-dependent enzymes in spermatozoa in patients with pathospermia]. Medical and Clinacal Chemistry, 18(4), 5-10 (in Ukrainian).

Raijmakers, M. T., Roelofs, H. M., Steegers, E. A., Steegers-Theunissen, R. R., Mulder, T. P., Knapen, M. F., Wong, W. Y, \& Peters, W. H. (2003). Glutathione and glutathione S-transferases A1-1 and P1-1 in seminal plasma may play a role in protecting against oxidative damage to spermatozoa. Fertility and Sterility, 79(1), 169-172.

Smirnov, L. P., \& Suhovskaya, I. V. (2014). Rol glutationa v funkcionirovanii system antioxidantnoi zaszyty i biotransformacii (Obzor) [Role of glutathione in antioxidant protection and biotransformation (Review)]. The Scientists Notes of Petrozavodsk State University. Biological Science, 143, $34-40$ (in Russian)

Spickett, C. M. (2013). The lipid peroxidation product 4-hydroxy-2-nonenal: advances in chemistry and analysis. Redox Biology, 1(1), 145-152.

Viloria, T., Meseguer, M., Martínez-Conejero, J. A., O’Connor, J. E., Remohí, J., Pellicer, A., \& Garrido, N. (2010). Cigarette smoking affects specific sperm oxidative defenses but does not cause oxidative DNA damage ininfertile men. Fertility and Sterility, 94(2), 631-637.

Wong, W. Y., Flik, G., Groenen, P. M., Swinkels, D. W., Thomas, C. M., Copius-Peereboom, J. H., Merkus, H. M., \& Steegers-Theunissen, R. P. (2001). The impact of calcium, magnesium, zinc, and copper in blood and seminal plasma on semen parameter in men. Reproductive Toxicology, 15(2), 131-136. 